\title{
What is the source of observed annual variations in plasmaspheric density?
}

\author{
S. M. Guiter ${ }^{1}$ \\ Space Sciences Laboratory, NASA Marshall Space Flight Center, Huntsville, Alabama \\ C. E. Rasmussen and T. I. Gombosi \\ Space Physics Research Laboratory, University of Michigan, Ann Arbor
}

\author{
J. J. Sojka and R. W. Schunk \\ Center for Atmospheric and Space Sciences, Utah State University, Logan
}

\begin{abstract}
Plasmaspheric densities have been observed previously to be higher in December than in June, with the ratio varying between 1.5 and 3.0 and with larger variations at lower $L$ shells. In order to search for the cause of the observed annual variations, we have modeled plasmaspheric density, using a time-dependent hydrodynamic model. On an $L=2$ field line with geomagnetic longitude equal to $300^{\circ}$, the modeled plasmaspheric densities were a factor of 1.5 times higher in December than in June. The modeled December to June density ratio was found to increase slightly with $L$ shell, in contrast to observations; this discrepancy may be due to the fact that outer plasmaspheric flux tubes are never completely full. In addition, for an $L=2$ field line with geomagnetic longitude equal to $120^{\circ}$, the modeled plasmaspheric density was higher in June than in December by a factor of about 1.2. Various numerical tests were also performed in order to examine the sensitivity of plasmaspheric density to various parameters. In particular, a large vertical neutral wind was applied in order to raise the $\mathrm{O}^{+}$profile, which had the effect of raising plasmaspheric density by a factor of 6 . This in conjunction with a theoretical analysis suggests that plasmaspheric density levels are very sensitive to $\mathrm{O}^{+}$levels in the upper ionosphere. We conclude that annual variations in plasmaspheric density are due to similar variations in ionospheric $\mathrm{O}^{+}$.
\end{abstract}

\section{Introduction}

Annual variations in plasmaspheric density have been found since the beginning of whistler research [Helliwell, 1961; Carpenter, 1962]. More recently, Park [1974] used whistler measurements made at Eights, Antarctica $\left(77^{\circ} \mathrm{W}\right.$ geographic longitude), to obtain the annual variation as a function of $L$ shell, for solar minimum and quiet geomagnetic conditions. His equatorial electron density profiles are shown in Figure 1. It can be seen that the densities in November and December are larger than those in June by a factor that varies between 1.5 and 3 , with larger variations at lower $L$ shells.

Although the annual variations in plasmaspheric density have been known for a long time, the cause is still not completely understood. Possible mechanisms which could be important include the following:

1. The tilt of the magnetic dipole axis from the rotation axis [cf. Helliwell, 1961; Carpenter, 1962; Park, 1974]. This leads to an annual variation in the total solar flux illuminating the conjugate ionospheres and different wind-induced vertical

\footnotetext{
${ }^{1}$ National Academy of Sciences/National Research Council Associate.

Copyright 1995 by the American Geophysical Union.

Paper number 94JA02866.

0148-0227/95/94JA-02866\$05.00
}

plasma drifts. The data presented by Park [1974] came from a longitude sector where both ends of a flux tube corotating with the Earth were illuminated each day for a longer period in December than in June. This mechanism would suggest a dependence of the annual variations on geographic longitude. The validity of this is enhanced by observations of increased density during June solstice in the opposite hemisphere $\left(37^{\circ} \mathrm{E}\right)$ at geosynchronous orbit [Song and Caudel, 1987]. Furthermore, Taylor [1971] made observations of the topside ionosphere which show a strong seasonal effect that depends on longitude. However, early whistler observations from stations that were widely separated in longitude suggest that the annual variation is global in scale and in phase everywhere [Park, 1974]. In addition, Clilverd et al. [1991], using a diffusive equilibrium model and published $f_{o} F 2$ values at conjugate stations, determined that there was only a slight annual variation in plasmaspheric density on field lines with average geographic longitudes of $50^{\circ} \mathrm{E}$ and $180^{\circ} \mathrm{E}$, with December values higher than June values.

2. Chemical equilibrium levels of $\mathrm{H}^{+}$in the middle ionosphere. If $\mathrm{H}^{+}$were substantially higher at the ends of a flux tube during certain periods of the year, this could raise $\mathrm{H}^{+}$ levels throughout the flux tube, including the plasmasphere.

3. Variations in $\mathrm{H}^{+}$scale height. If plasmaspheric temperatures were higher in December than in June, this could raise plasmaspheric densities without having to increase $\mathrm{H}^{+}$levels at the ends of the flux tube. 


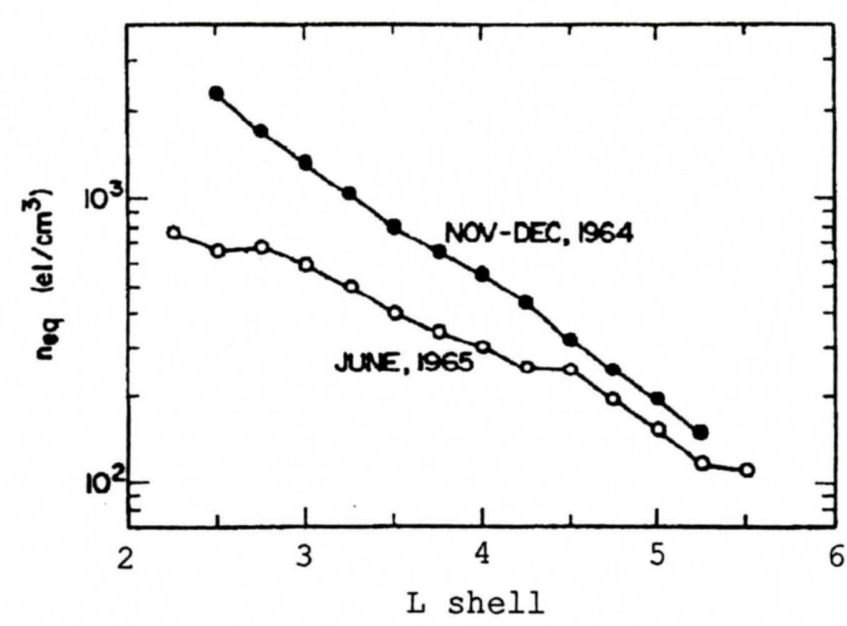

Figure 1. Equatorial electron density as a function of $L$ shell, taken from Park [1974].

4. Variations in the production or loss rates of $\mathrm{H}^{+}$in the upper ionosphere, where transport processes dominate and $\mathrm{H}^{+}$ is no longer in chemical equilibrium. Hydrogen ions are created by charge exchange of $\mathrm{O}^{+}$with atomic hydrogen and lost via charge exchange of $\mathrm{H}^{+}$with atomic oxygen. Significant changes in the neutral atmosphere or in $\mathrm{O}^{+}$levels could lead to annual plasmaspheric variations.

5. $\mathrm{O}^{+}$levels in the upper ionosphere. As will be shown later, when in diffusive equilibrium, plasmaspheric densities are dependent upon $\mathrm{H}^{+}$densities at the crossover point (where $\mathrm{H}^{+}$becomes the dominant ion), which in turn depend on $\mathrm{O}^{+}$ densities in the upper ionosphere. This is supported by observations [Clilverd et al., 1991; Lal, 1992] which show that $F 2$ peak densities are higher in December than in June. In addition, previous modeling work [Clilverd et al., 1991; Rippeth et al. , 1992] has shown that the annual variation of plasmaspheric density is correlated with the annual variation of $F_{2}$ peak density.

Our intentions in this paper are as follows. First, numerical solutions of our plasmaspheric model are reported for $L=2$, which show an annual variation in plasmaspheric density, similar to the variation that has been observed (however, we were unable to reproduce the factor of $\sim 3$ variation that has been observed [Park, 1974; Clilverd et al., 1991] on field lines with $L \sim 2$ and zero degrees geomagnetic longitude). Second, ionospheric parameters calculated by the model will be examined to help understand why the annual variations predicted at $L=2$ occur. Third, results for different $L$ shells and longitudes will be reported. Fourth, the results from various numerical tests will be given. These were done to test hypothesis 5 , as given above. Then in the concluding section we will summarize our results.

\section{Model Results at $L=2$}

In order to model annual variations in plasmaspheric density, diurnally reproducible solutions for June and December solstices were found by using a coupled ionosphere-plasmasphere model. This model solves the time-dependent continuity, momentum, and energy equations for $\mathrm{O}^{+}$and $\mathrm{H}^{+}$from $200 \mathrm{~km}$ in one ionosphere to $200 \mathrm{~km}$ in the conjugate ionosphere. In the runs presented here, the model is the same as that described by Guiter et al. [1991], except for a few changes. In the current version of the model, neutral winds are found by using the vector spherical harmonic (VSH) model described by Killeen et al. [1987] and depend on the hemi. sphere. Also, electron heating rates above $800-\mathrm{km}$ altitude were calculated assuming a direct dependence on electron number density and an inverse dependence on flux tube area. The inverse dependence on flux tube area is justified if the number of photoelectrons is approximately constant. Minimum heating rates were imposed so that $25 \%$ to $30 \%$ of the upward photoelectron flux is degraded by interactions with thermal electrons. The percentage of photoelectron flux degraded was chosen so that modeled temperatures would match observations of plasmaspheric temperature [Comfort et al., 1985]. In addition, heating rates below $800 \mathrm{~km}$ were modified in a way that allowed for the possibility that one hemisphere may be in sunlight while the other is in darkness.

For the present work, solar minimum conditions were assumed. The geographic coordinates of the ends of the model flux tube for the initial runs were $\left(37.7^{\circ} \mathrm{N}, 121.6^{\circ} \mathrm{W}\right)$ and $\left(48.9^{\circ} \mathrm{S}, 140.8^{\circ} \mathrm{W}\right)$, which correspond to a geomagnetic longitude of $300^{\circ}$ and an $L=2$ field line. The results from the computer simulation of June and December solstice conditions are shown in Figure 2, where plasmaspheric $\mathrm{H}^{+}$density at the equator is plotted as a function of local time. There is a clear increase in density during December with a ratio of plasmaspheric density in December to that in June of approximately 1.5. This ratio is nearly constant throughout the diurnal cycle. Our results are consistent with the whistler measurements made at approximately $300^{\circ} \mathrm{E}$ geomagnetic longitude by Carpenter [1962], who reported January to June ratios of 1.2 to 1.5 (in the latitude range from $L=2$ to $L=4$ ); however, these results were for solar maximum to medium conditions, with $K p$ values less than or equal to 5 . Our results are roughly a factor of 2 lower than the variations observed by Park [1974], who found November and December densities to be 1.5 to 3 times larger than June values, with the ratio increasing with decreasing $L$.

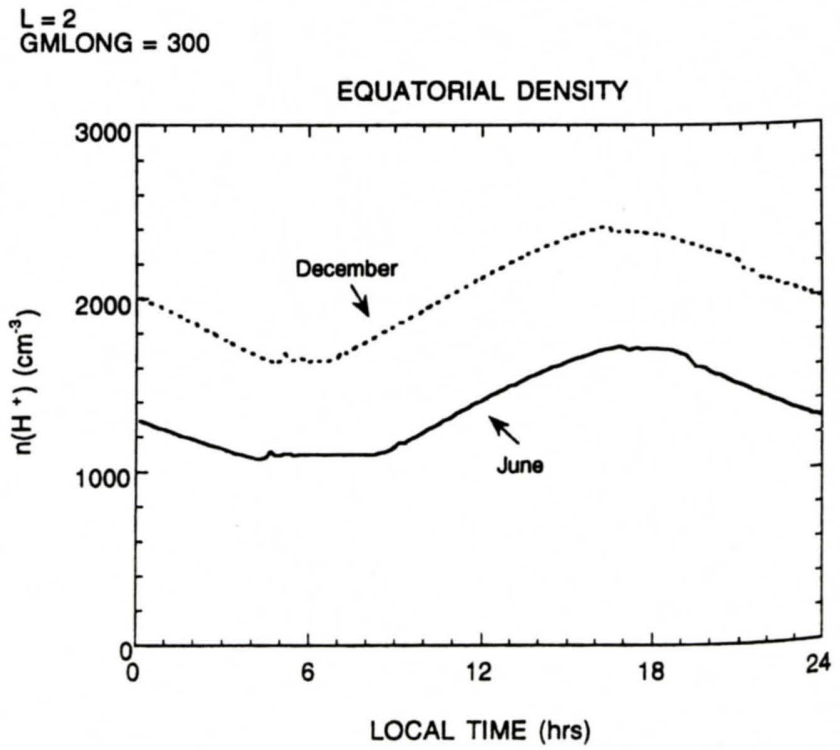

Figure 2. Diurnal variation of plasmaspheric density. $\mathrm{H}^{+}$ concentrations for June (solid line) and December (dashed line) solstices are shown as a function of local time. 
In addition, Clilverd et al. [1991] found the December to June plasmaspheric density ratio to be about 3.0 on a field line with $L=2.5$ and in the same longitude region as the Park [1974] work. These measurements [Park, 1974; Clilverd et al., 1991] were done for field lines with geomagnetic longitude near zero degrees, which are shifted farther south compared to the field line at $300^{\circ} \mathrm{E}$ geomagnetic; for both longitudes the ionospheres are exposed to sunlight longer in December than in June but the disparity is enhanced at zero degrees longitude. To see whether this causes significant differences, model results were found for December and June solstices on an $L=2$ field line with geomagnetic longitude equal to zero. For this longitude the modeled December to June plasmasphere density ratio varied between 1.6 and 1.8 , which is only slightly higher than the ratio on the field line with geomagnetic longitude equal to $300^{\circ}$.

Although the model predicts the same sense of variation and roughly the correct magnitude as the measurements, the question remains as to the cause of the annual variations. As discussed in the introduction, there are many possible mechanisms. Our intention is to use our modeling results to understand why the December densities obtained in our model runs were higher than those in June. However, it is not immediately clear how to do this. For instance, at what altitude should one begin to look for ionospheric parameters that can lead to annual variations in the plasmasphere? Is the $F$ region the critical location, or are higher altitudes more importantperhaps the transition region where $\mathrm{H}^{+}$becomes the dominant ion species? Also, which time period is more important, day or night?

\subsection{Theoretical Analysis}

Rasmussen et al. [1993] have derived approximate analytical expressions to treat plasmasphere refilling. These expressions are now exploited to seek potential mechanisms which may be responsible for the annual variations in plasmaspheric density. The time rate of change of the spatially averaged (along a field line) density in the plasmasphere, $\bar{n}$, is approximated by

$$
\frac{\partial \bar{n}}{\partial t}=\sum_{s=S, W} \frac{n_{s}-\bar{n}}{\tau_{s}}
$$

where $t$ is time, $n_{s}$ is the saturation density of a full flux tube, and $\tau_{s}$ is the refilling time constant. The sum in (1) is over the two conjugate hemispheres. Note that in general, both the saturation density and the refilling time depend on the hemisphere. This is especially true for the solstice conditions considered here, when one hemisphere is in summer $(S)$ and the other is in winter $(W)$.

The total tube content of a corotating flux tube can change appreciably only as a result of ions which enter or leave the tube at the ionospheric boundary. Equation (1) is a statement of this conservation with the right-hand side representing the effects of ionospheric fluxes through the lower boundary of the plasmasphere. These fluxes are approximated in (1) by assuming that equilibrium densities are approached at a rate that depends on the variation from equilibrium and a time scale $\tau$ [Krinberg and Tashchilin, 1982; Rasmussen et al., 1993]. The spatially averaged plasmaspheric density was shown by Rasmussen et al. [1993] to be a good approximation to plasmaspheric densities near the equator (the peak altitude of the flux tube). At $L=2$, they found that $\bar{n}$ differed from the equatorial density $n_{e q}$ by only $10 \%$. At higher $L$ values the agreement was even better. Therefore in what follows, $\bar{n}$ is used as a synonym for $n_{e q}$.

Equation (1) can be simplified by averaging in time over a complete diurnal cycle. Because the plasmasphere is assumed to be full, the time average of the left-hand side of (1) is zero. The time average of the right-hand side yields

$$
\sum_{s=S, W}\left\langle\frac{\bar{n}}{\tau_{s}}\right\rangle=\sum_{s=S, W}\left\langle\frac{n_{s}}{\tau_{s}}\right\rangle
$$

where the angle brackets denote time-averaged quantities. It should be noted that the saturation density $n_{s}$ is not a constant. It represents the equatorial density that would occur if the plasmasphere were allowed to come to an equilibrium while holding ionospheric parameters fixed. Because no interhemispheric flow is allowed during this (imaginary) process, saturation densities for the two conjugate ionospheres are in general different. As ionospheric parameters are constantly changing, so also is $\boldsymbol{n}_{\boldsymbol{s}}$.

A scaling law for the average plasmaspheric density can be obtained by assuming that the refilling time scales in (2) are constant in time and independent of hemisphere. In this instance,

$$
\langle\bar{n}\rangle \cong \frac{\left\langle n_{S}\right\rangle+\left\langle n_{W}\right\rangle}{2}
$$

where $n_{S}$ and $n_{W}$ represent the saturation densities of the summer and winter hemispheres, respectively. The dominant factors in (2) appear to be the saturation densities. The $\tau$ terms, which are ignored in (3), are weighting factors which are responsible for balancing differences between the summer and winter hemispheres and differences in time. For instance, if the time scales $\tau_{s}$ are much smaller during the night than during the day (at night, $\tau_{s}$ is a time scale for emptying), the $\tau$ weighting in (2) would favor nighttime saturation densities, and $\langle\bar{n}\rangle$ would be nearer to nighttime $n_{s}$ than daytime $n_{s}$.

In fact this superficial example may actually represent realworld conditions. The refilling time constant can be expressed as [Rasmussen et al., 1993]

$$
\tau_{s}=\frac{n_{s} V / A_{i}}{F_{s}}
$$

where $V$ is flux tube volume, $A_{i}$ is the area of the flux tube at the ionosphere, and $F_{s}$ is the limiting ionospheric flux (see Geisler [1967] or Richards and Torr [1985]), obtained when the plasmasphere is empty. As will be shown below, $n_{s}$ is proportional to ionospheric $\mathrm{O}^{+}$; thus $n_{s}$ and $\tau_{s}$ will frequently be lower at night. The interesting conclusion from this analysis is that $\mathrm{H}^{+}$levels in the full plasmasphere are largely controlled by ionospheric conditions at night.

Saturation densities $n_{s}$ can be mapped down to an altitude $z_{t r}$ in their respective ionospheres by assuming a constant $\mathrm{H}^{+}$ scale height. Thus $n_{s}\left(z_{e q}\right)$ is proportional to $n_{s}\left(z_{t r}\right)$, where $z_{e q}$ is altitude at the equator and $z_{t r}$ is taken to be the altitude where the saturated $\mathrm{H}^{+}$profile (obtained by assuming no bulk transport of $\mathrm{H}^{+}$between the ionosphere and plasmasphere) crosses the ionospheric $\mathrm{O}^{+}$profile (see Figure 3). An approximation for $n_{s}\left(z_{t r}\right)$ can be obtained by mapping chemical equilibrium levels of $\mathrm{H}^{+}$, 

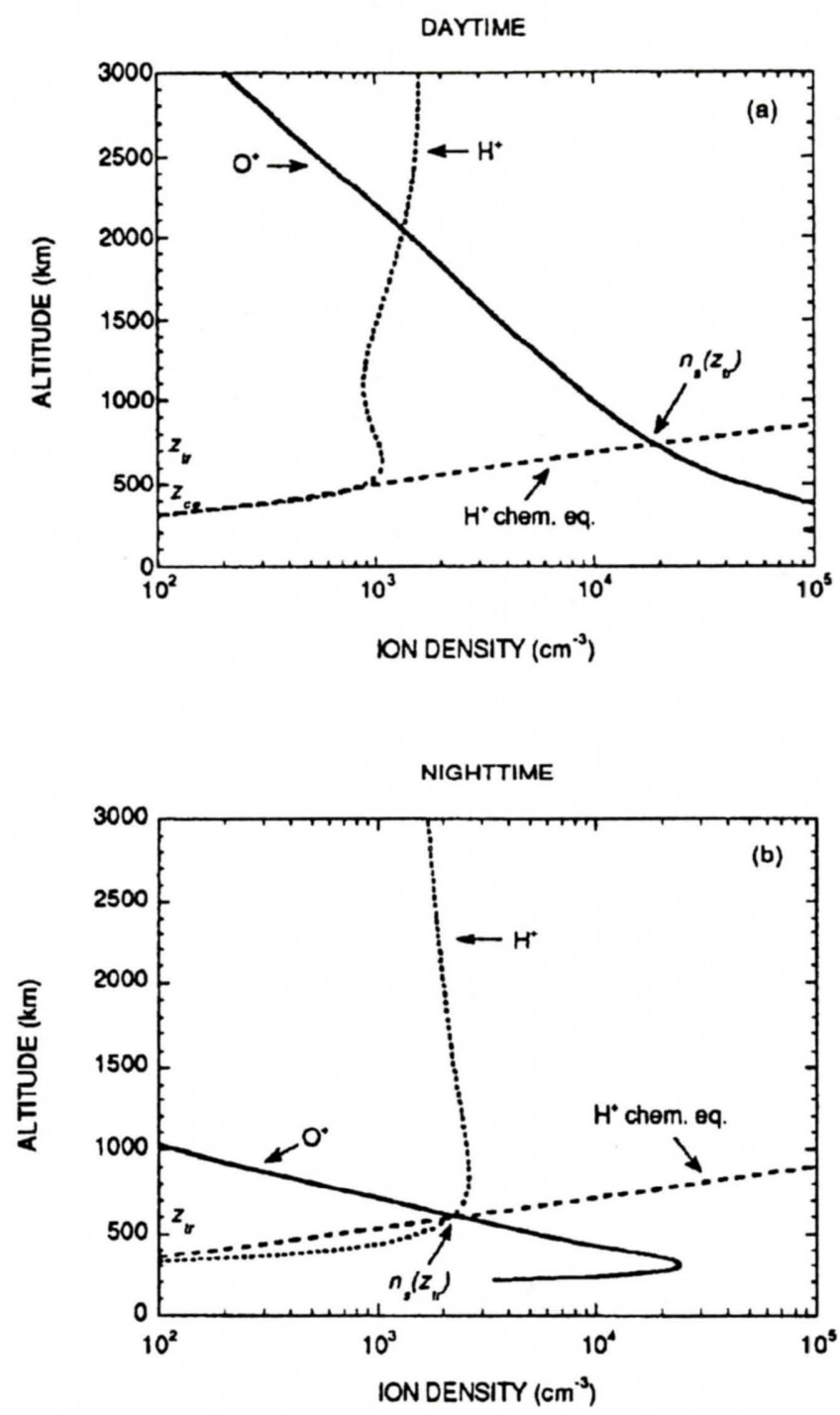

Figure 3. Altitude profiles of $\mathrm{O}^{+}$and $\mathrm{H}^{+}$density and of the chemical equilibrium $\mathrm{H}^{+}$density for (a) $1200 \mathrm{LT}$ and (b) 2400 LT. The labeled altitudes are $z_{c e}$, altitude below which $\mathrm{H}^{+}$is in chemical equilibrium, and $z_{t r}$, the approximate transition altitude for a saturated flux tube.

$$
n\left(z_{c e}\right)=\left[O^{+}\right] \frac{L_{O^{+}}}{L_{H^{+}}}
$$

up to $z_{t r}$, where $L_{O^{+}}=2.5 \times 10^{-11} T_{n}{ }^{1 / 2}[\mathrm{H}]$ is the $\mathrm{O}^{+}$loss frequency, $L_{H^{+}}=2.2 \times 10^{-11} T_{i}^{1 / 2}[\mathrm{O}]$ is the $\mathrm{H}^{+}$loss frequency, and $T_{n}$ and $T_{i}$ are the neutral and ion temperatures, respectively. This mapping is done by assuming that $\mathrm{H}^{+}$is a minor species below $z_{t r}$, and thus the diffusive equilibrium profile of $\mathrm{H}^{+}$is controlled by the ambipolar electric field due to the major ion $\mathrm{O}^{+}$. By solving for $\mathrm{H}^{+}$levels at the crossover point $z_{t r}$, it can be shown that

$$
n_{s}\left(z_{t r}\right)=\left[O^{+}\right] \sqrt{\frac{L_{O^{+}}}{L_{H^{+}}}}
$$

where [ $\left.\mathrm{O}^{+}\right], L_{O}{ }^{+}$, and $\mathrm{LH}_{H}{ }^{+}$on the right-hand sides of (5) and (6) are taken at the altitude, $z_{c e}$ (the top of the region where $\mathrm{H}^{+}$is in chemical equilibrium) [Rasmussen et al., 1993]. Because the diffusion and chemical scale heights of $\mathrm{H}^{+}$are approximately equal [Geisler, 1967], the saturation levels $n_{s}\left(z_{t r}\right)$ are not very sensitive to the choice of $z_{t r}$.

In summary, the plasmasphere is constantly trying to reach a state such that it is in equilibrium with the saturation densities, $n_{s}\left(z_{t r}\right)$, existing in each hemisphere. These densities are constantly changing during the diurnal cycle, as can be seen in Figure 3. During the daytime, $n_{s}\left(z_{t r}\right)$ is relatively high as a consequence of higher $\mathrm{O}^{+}$densities, and $\mathrm{H}^{+}$flows from the ionosphere into the plasmasphere as an equilibrium distribution is sought. (Ions also flow into the plasmasphere during the daytime, solely in response to an increase in plasmaspheric temperature.) During the nighttime, $n_{s}\left(z_{t r}\right)$ drops, the plasmasphere becomes overfull, and $\mathrm{H}^{+}$flows back into the ionosphere, where it can be lost via charge exchange with atomic oxygen. Any imbalance between the saturation densities in the summer and winter hemispheres results in an interhemispheric flow of $\mathrm{H}^{+}$.

An annual variation in any of the parameters in (6) is likely to cause a corresponding variation in plasmaspheric density. We search for possible annual variations in these parameters in the next section.

\subsection{Diurnal Averages}

In order to eliminate one of the many degrees of freedom, diurnal averages of various quantities from the model runs at $L$ $=2$ have been found. These average quantities are now examined to try and ascertain how they relate to the increased December densities shown in Figure 2. This averaging is also consistent with the approximations obtained in the preceding section and will allow a check to see whether the results of the numerical model scale approximately as the ionospheric saturation density given in (6).

Diurnally averaged $\mathrm{O}^{+}$profiles are shown in Figure 4. In this and the following plots of average quantities, the solid lines refer to June results while the dashed lines give December results. Average $\mathrm{O}^{+}$is seen to be substantially higher in December than in June at all altitudes. This is especially true in the winter hemisphere, where $\mathrm{O}^{+}$is 1.9 times higher in December at $500 \mathrm{~km}$ than in June. This ratio is somewhat lower in the summer hemisphere, where $\mathrm{O}^{+}$is 1.3 times higher in December (also at $500 \mathrm{~km}$ ). The average of these two ratios is 1.6 , which is very close to the amount that plasmaspheric densities were modeled to have increased in December. It should be noted that Clilverd et al. [1991], using ionosonde data from Argentine Islands and Wallops Island, found that the December to June ratio of $F 2$ peak densities was correlated with the ratio of plasmaspheric densities.

Other parameters related to the saturation densities in (6) are the loss frequencies, $L_{H}{ }^{+}$and $L_{O}{ }^{+}$These parameters also appear in the chemical equilibrium values of $\mathrm{H}^{+}$described by (5). What is surprising is that average chemical equilibrium levels do not show significant annual variations. This can be seen in Figure 5, where no noteworthy differences occur in average $\mathrm{H}^{+}$ levels below $400 \mathrm{~km}$. It is only at higher altitudes that average December levels become substantially larger than June levels. At these altitudes, $\mathrm{H}^{+}$is no longer in chemical equilibrium, and transport becomes increasingly important. That $\mathrm{H}^{+}$equilibrium concentrations do not vary appreciably is surprising, because $\mathrm{O}^{+}$, which is partially responsible for equilibrium $\mathrm{H}^{+}$, does change significantly from December to June, as was seen in Figure 4. What occurs is that the ratio $L_{O}{ }^{+} / L_{H}{ }^{+}$also changes and in a direction opposite to the $\mathrm{O}^{+}$variations. The net result 

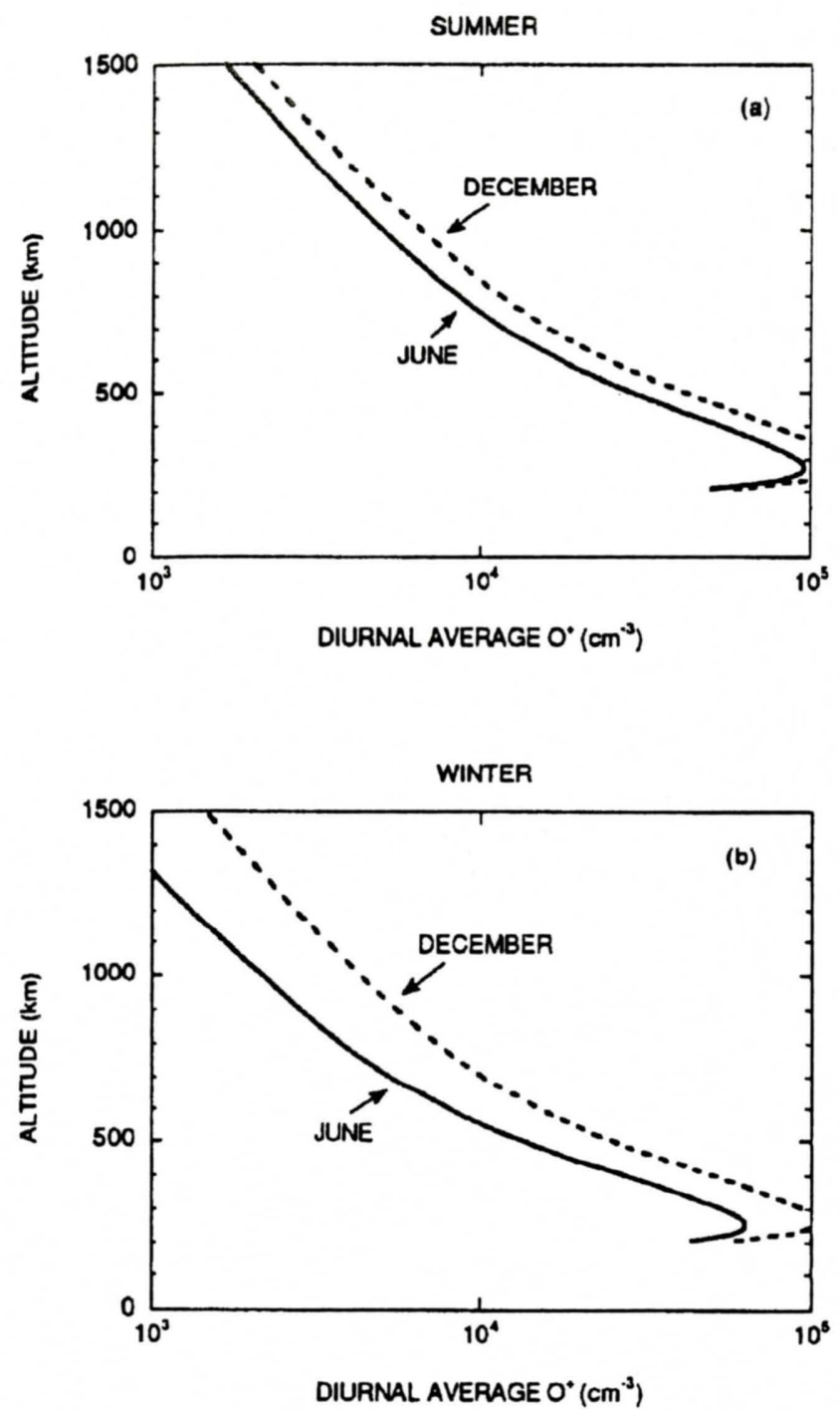

Figure 4. Diurnally averaged $\mathrm{O}^{+}$concentrations for June (solid line) and December (dashed line) solstices. Densities in the (a) summer and (b) winter hemispheres are shown.

is that chemical equilibrium values change only slightly. However, in (6), the loss rates appear under the square root, and their effect is reduced in the calculation of saturation densities. Thus of the quantities in (6) affecting plasmaspheric density, ionospheric $\mathrm{O}^{+}$is considered to be the most likely candidate for the cause of the annual plasmaspheric variations.

Temporal variations in other quantities have also been considered to see whether mechanisms other than those associated with the saturation densities, $n_{s}\left(z_{t r}\right)$ may play a role in the annual plasmaspheric variations. Diurnal average production rates of $\mathrm{H}^{+}$were found to be significantly higher in December than in June, as would be expected from the higher average $\mathrm{O}^{+}$ levels. Average loss rates of $\mathrm{H}^{+}$were also found to be higher in December. This should not be surprising, because in diurnal equilibrium, net production must equal net loss. Average interhemispheric fluxes were found to be higher in December than in June, indicative of a somewhat larger hemispheric asymmetry in December. The neutral atmosphere displayed an annual variation through the loss rates, $\mathrm{LH}_{\mathrm{H}}^{+}$and $\mathrm{LO}_{\mathrm{O}^{+}}$, described above.
One might at first expect $\mathrm{H}^{+}$production rates to be directly relevant to annual plasmaspheric variations. After all, as more $\mathrm{H}^{+}$is produced, higher $\mathrm{H}^{+}$levels are expected as well. However, most $\mathrm{H}^{+}$is produced in the middle ionosphere below $500 \mathrm{~km}$. The problem is not only to produce $\mathrm{H}^{+}$, but to transport it into the plasmasphere as well. To reach the plasmasphere, $\mathrm{H}^{+}$must diffuse through $\mathrm{O}^{+}$, and only at altitudes where $\mathrm{O}^{+}$has fallen below a certain level can $\mathrm{H}^{+}$freely escape. What is important is to produce $\mathrm{H}^{+}$in the upper regions of the ionosphere where it can freely escape into the plasmasphere. Of course, $\mathrm{O}^{+}$levels are important in the production of $\mathrm{H}^{+}$, but since $\mathrm{O}^{+}$also directly retards the flow of $\mathrm{H}^{+}$, mechanisms associated solely with production rates are not likely to directly cause the annual plasmaspheric variations.

Other model parameters, which might have been potentially important, were found to show little annual variation. These included the ion and electron temperatures and $\mathrm{H}^{+}$levels below $400 \mathrm{~km}$, where hydrogen ions are in chemical equilibrium with $\mathrm{O}^{+}$. Thus we conclude that of the possible mechanisms that might potentially be responsible for the annual plasmaspheric variations, it is most likely that $\mathrm{O}^{+}$levels in the upper iono-
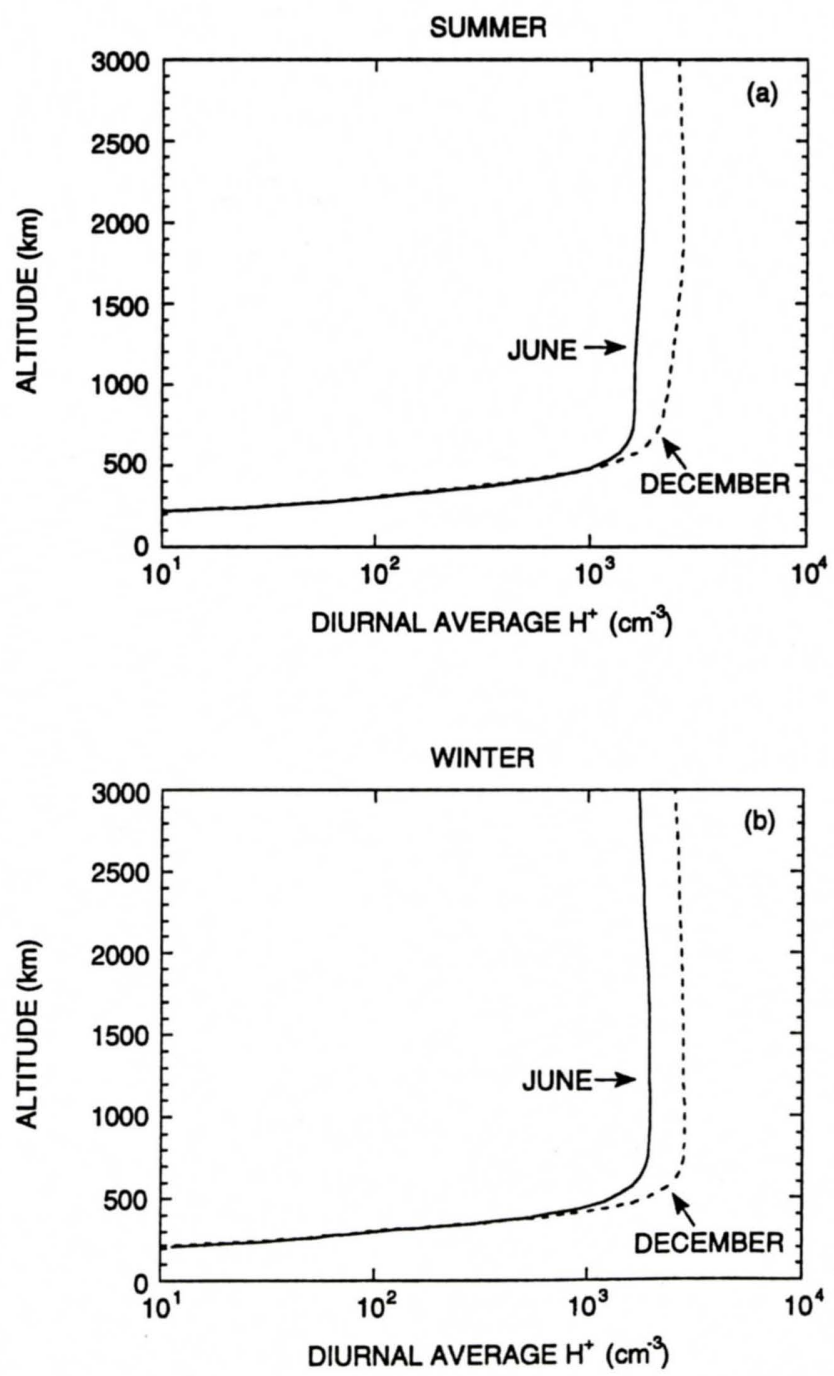

Figure 5. Diurnally averaged $\mathrm{H}^{+}$concentrations for June (solid line) and December (dashed line) solstices. Densities in the (a) summer and (b) winter hemispheres are shown. 
sphere have the dominant effect. Increases in $\mathrm{O}^{+}$directly affect plasmaspheric densities by increasing the $\mathrm{O}^{+}-\mathrm{H}^{+}$transition height. Because chemical equilibrium $\mathrm{H}^{+}$concentrations increase with altitude below the transition height, $z_{t r}$, as the transition height increases, $n_{s}\left(z_{t r}\right)$ and plasmaspheric $\mathrm{H}^{+}$density must increase as well.

\section{Latitude and Longitude Dependence}

Results were found for June and December solstice on field lines with $L$ values of 3 and 4 , with the geomagnetic longitude equal to $300^{\circ}$. For each of these cases the model was run until it was diurnally reproducible; the flux tubes were assumed to corotate. Figure 6 shows the equatorial density at 2400 LT vs. $L$ shell, with the model results indicated by the circles and squares. As can be seen from the figure, December densities are greater than June densities on $L$ shells between 2 and 4 for this particular longitude. Our model results show that the December to June ratio increases slightly with $L$ value, whereas the Park [1974] measurements indicate that this ratio decreases sharply with $L$ (see Figure 1). Furthermore, the modeled densities at $L=$ 3 and 4 are significantly higher than the densities observed by Park [1974], with the discrepancy greater at $L=4$. While these discrepancies are not fully understood, they could be related to the fact that flux tubes in the outer plasmasphere are never completely full [cf. Park, 1974]; this is supported by the greater disparity at the higher $L$ shell. In addition, modeling results of Rippeth et al. [1992] show that the December to June plasmaspheric density ratio increases as the flux tube fills; they used an interhemispheric ionosphere-plasmasphere model which includes an eccentric dipole geomagnetic field.

The longitude dependence of the annual variations was tested by finding results for June and December solstice for $L=$ 2 and geomagnetic longitude equal to $120^{\circ}$. For this longitude the northern end of the flux tube is farther from the geographic equator than the southern end, and the ionospheres are exposed to sunlight longer in June than in December. The geographic coordinates of the ends of the model flux tube are approxi-

\section{GMLONG $=300$}

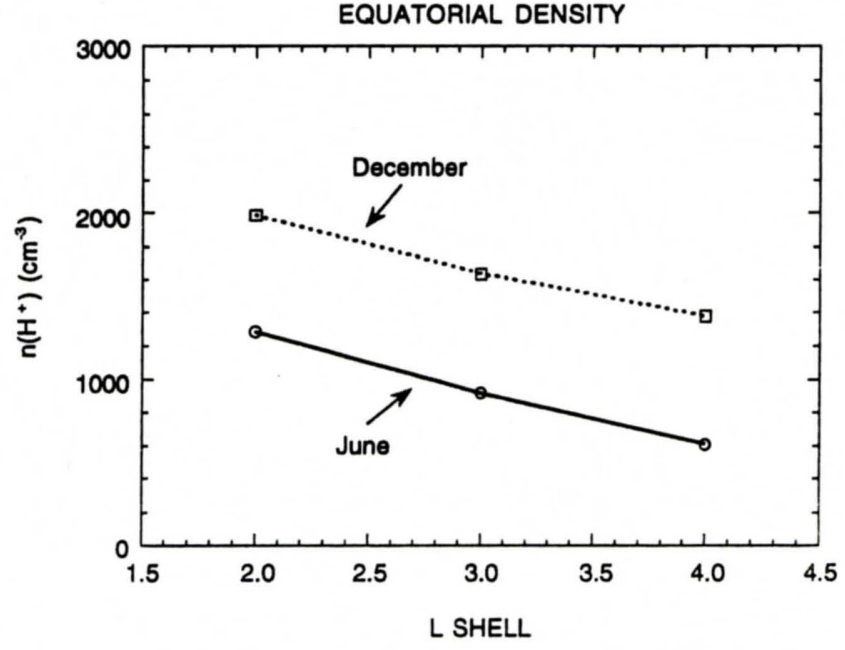

Figure 6. Equatorial $\mathrm{H}^{+}$density at $2400 \mathrm{LT}$ for June (solid line) and December (dashed line) solstices as a function of $L$ shell. mately $\left(48.9^{\circ} \mathrm{N}, 39.2^{\circ} \mathrm{E}\right)$ for the northern end and $\left(37.7^{\circ} \mathrm{S}\right.$, $58.4^{\circ} \mathrm{E}$ ) for the southern end. In this case, the June density is greater than the December density for all local times; the June to December ratio varies between 1.2 and 1.3. The diurnal variation is similar to that found when the geomagnetic longitude was $300^{\circ}$ (see Figure 2). It should be noted that Rippeth et al. [1992] found the December to June plasmaspheric density ratio to be 0.9 on an $L=2.5$ field line with the equatorial geographic longitude equal to $47^{\circ} \mathrm{E}$. The equatorial densities at 2400 LT are shown in Table 1, along with results from various numerical tests which will be discussed in the next section. In this case too, average $\mathrm{O}^{+}$levels are predictors of plasmaspheric levels; i.e., diurnally averaged $\mathrm{O}^{+}$density is greater in June than in December (in both the winter and summer hemispheres, with the difference larger in the winter hemisphere). This increase in $\mathrm{O}^{+}$is due both to increased photoionization and to higher atomic oxygen densities.

An annual variation with the maximum in June was found by Song and Caudel [1987] for $L=6.6$ and geographic longitude equal to $37^{\circ} \mathrm{E}$. Using GEOS 2 data, they found that the June to December ratio of monthly averaged electron density was about 1.2, but it should be noted that the June density was significantly greater only in the afternoon. However, Tarcsai et al. [1988] used whistler data recorded at Tihany, Hungary ( $\sim 8^{\circ} \mathrm{E}$ geographic longitude), to show that for $L>2.4$ there was no significant annual variation; for $1.6<L<2.2$ there was a slight variation, with December values higher than June values. Furthermore, Clilverd et al. [1991], using a diffusive equilibrium model and published $f_{o} F 2$ values at conjugate stations, determined that there was only a slight annual variation in plasmaspheric density on field lines with average geographic longitudes of $50^{\circ} \mathrm{E}$ and $180^{\circ} \mathrm{E}$ and with $L$ values equal to 3.5 and 4.2, with December values higher than June values. In addition, Clilverd et al. [1991] used whistler data recorded in New Zealand $\left(L=2.2\right.$, geographic longitude $\left.\sim 180^{\circ} \mathrm{E}\right)$ to confirm these results.

\section{Numerical Tests}

In this section the results of various numerical tests are described. These were done to test the hypothesis that ionospheric $\mathrm{O}^{+}$densities are responsible for annual variations in the plasmasphere. They were all done for a field line with $L=2$ and geomagnetic longitude equal to $300^{\circ}$. The second and third tests were done to investigate the separate roles of the neutral atmosphere and of solar illumination.

\subsection{Inclusion of a Vertical Neutral Wind}

In order to test the sensitivity of plasmaspheric densities to $\mathrm{O}^{+}$densities in the upper ionosphere, a vertical neutral wind was included in order to raise the $\mathrm{O}^{+}$profile without changing

Table 1. Equatorial Densities for $L=2$ at $2400 \mathrm{LT}$

\begin{tabular}{lll}
\hline \multicolumn{1}{c}{ CaselMonth } & June & December \\
\hline gmlong $=300$ (original run) & $1.3 \times 10^{3}$ & $2.0 \times 10^{3}$ \\
gmlong $=120$ & $1.8 \times 10^{3}$ & $1.5 \times 10^{3}$ \\
gmlong $=0$ & $1.3 \times 10^{3}$ & $2.3 \times 10^{3}$ \\
Vertical wind imposed & $8.2 \times 10^{3}$ & \\
Neutral parameters switched & $1.6 \times 10^{3}$ & $2.4 \times 10^{3}$ \\
Photoproduction rates & $1.7 \times 10^{3}$ & $2.3 \times 10^{3}$ \\
\hline
\end{tabular}

Values are in units per cubic centimeter. 
other parameters. The magnitude of this vertical wind was 100 $\mathrm{m} / \mathrm{s}$. This was done for June solstice conditions. The $F 2$ peak electron density went up by a factor of about 2.4 at 1200 LT and by a factor of about 8.5 at 2400 LT. The peak height increased by about $50 \mathrm{~km}$ at $1200 \mathrm{LT}$ and by about $20 \mathrm{~km}$ at 2400 LT. The plasmaspheric density increased considerably when the vertical wind was included, by a factor of about 6.1 at $1200 \mathrm{LT}$ and 6.4 at $2400 \mathrm{LT}$. This is further evidence of the considerable control that ionospheric $\mathrm{O}^{+}$has on plasmaspheric density levels. It should also be noted that the model results of Rippeth et al. [1992] show that the degree of correlation between $N_{m} F 2$ ratios and plasmaspheric density ratios depends on the neutral wind profile.

\subsection{Interchange of Neutral Densities and Temperatures Between Hemispheres}

The dependence of the annual variation on neutral parameters was tested by switching the neutral densities and temperatures between hemispheres. However, the calculated photoionization production rates were not switched. This change would affect the production rates of $\mathrm{O}^{+}$due to charge exchange with $\mathrm{H}^{+}$and also the $\mathrm{O}^{+}$loss rates. This was done for both June and December solstice conditions. It was found that the equatorial density at $2400 \mathrm{LT}$ increased by a factor of about 1.5 in June and about 1.2 in December. The December to June ratio was somewhat lower in this case, about 1.2; originally the December to June ratio was about 1.5.

\subsection{Interchange of Photoproduction Rates Between Hemispheres}

Finally, the dependence of the annual variation on photoproduction rates was tested by switching the photoionization production rates between hemispheres, without changing the neutral densities and temperatures. This was done for June and December solstice conditions. The equatorial density at 2400 LT increased by a factor of about 1.3 in June and about 1.1 in December. The December to June ratio was about 1.3.

In summary, three numerical tests were done. The most striking results were found when a vertical wind, with magnitude equal to $100 \mathrm{~m} / \mathrm{s}$, was included in order to raise the $\mathrm{O}^{+}$profile. In this case the plasmaspheric density went up by a factor of about 6 , showing how ionospheric $\mathrm{O}^{+}$can control plasmaspheric density levels. The other two tests involved interchanging first the neutral densities and temperatures and then the photoionization production rates between hemispheres, for both June and December solstice conditions. In each case the December to June density ratio was lowered (by about the same amount in each case) but was still greater than one. This happened because plasmaspheric densities in June increased considerably, whereas those in December only slightly increased. This probably reflects the much larger value that the average photoionization coefficient (the ratio of the photoproduction rate to the atomic oxygen density) has in the December summer hemisphere compared to other hemispheres (as a result of more exposure to sunlight), which means that the December summer $\mathrm{O}^{+}$levels would be higher and not as affected by changes in other parameters. In turn, the December plasmaspheric density would be determined largely by the summer $\mathrm{O}^{+}$density in the upper ionosphere and hence would not change as much as the June plasmaspheric density. That the results were about the same in the second and third cases suggests that the neutral atmosphere and solar illumination are equally important for producing the annual variation in plasmaspheric density.

\section{Discussion}

Torr and Torr [1973] did a global study of the seasonal behavior of electron density in the $\mathrm{F}_{2}$ layer, where $\mathrm{O}^{+}$is the dominant ion. They found that during solar maximum conditions, most of the northern hemisphere and a region in the southern hemisphere have the highest $F 2$ peak electron densities during the winter rather than the summer, and the term winter anomaly has been applied to this relationship. In the South Pacific and South Atlantic regions the highest ionospheric densities occur during the summer; this appears to be due to charged particle precipitation in regions surrounding the geomagnetic anomaly. However, over much of the southern hemisphere the highest electron density occurs near the equinoxes. During solar minimum conditions the South Atlantic anomaly plays an important role for field lines whose southern end is in this region. Particle precipitation in this region causes enhanced heating, which enhances convection of atomic oxygen from the southern summer hemisphere to the northern winter hemisphere and inhibits the reverse flow (northern summer to southern winter).

Previous modeling studies [Rees et al., 1988; Sojka and Schunk, 1989] have shown the existence of the winter anomaly for solar maximum conditions. Rees et al. [1988], using a coupled thermosphere/polar ionosphere model, found the winter anomaly in the northern polar ionosphere for magnetic latitudes greater than $55^{\circ}$. Sojka and Schunk [1989] used a global ionosphere model, with neutral densities taken from the MSIS 77 model [Hedin et al., 1977], to show that the winter anomaly existed in the northern hemisphere at all universal times between magnetic latitudes of $30^{\circ}$ and $60^{\circ}$.

Our study, for solar minimum conditions, showed that average $\mathrm{O}^{+}$density in the northern hemisphere exhibited the winter anomaly when the geomagnetic longitude was $300^{\circ}$ but not when the geomagnetic longitude was $120^{\circ}$; in the southern hemisphere the winter anomaly was not present at either longitude. Since the southern end of a field line with geomagnetic longitude equal to $300^{\circ}$ is approximately in the South Atlantic anomaly region, this would be consistent with the results of Torr and Torr [1973] for solar minimum conditions.

We suggest that the observed annual variations in plasmaspheric density near $300^{\circ}$ geomagnetic longitude are due to the lack of a winter anomaly in the southern hemisphere. $\mathrm{O}^{+}$ densities are higher in December than in June for both the northern hemisphere (for which there is a winter anomaly) and the southern hemisphere. This is supported by observational results of Lal [1992], which show that globally averaged $F 2$ peak densities are higher in December than in June, with the ratio being approximately 1.2 .

Finally, the question remains as to why $\mathrm{O}^{+}$levels vary. The $\mathrm{O}^{+}$densities will depend upon the amount of time that an ionosphere is sunlit and also upon neutral species densities, particularly atomic oxygen and hydrogen in the upper ionosphere. Torr et al. [1980] have shown that the observed variations in $\mathrm{O}^{+}$density at the $F 2$ peak, including the seasonal anomaly, can largely be explained in terms of seasonal and geographic variations in neutral densities if the correct thermospheric chemistry is assumed. In addition, for solar maximum conditions, production of $\mathrm{N}_{2}$ vibrational excitations is high enough to reduce the peak electron density by an 
additional 30\% in summer [Torr et al., 1980]. It can be seen that the neutral atmosphere plays a very large role in determining the annual variation in plasmaspheric density, not directly through $\mathrm{H}^{+}$density levels, but indirectly by controlling $\mathrm{O}^{+}$ densities. In addition, neutral wind profiles and photoionization rates also have a role in determining the annual variation.

\section{Conclusions}

We have shown that for a field line whose geomagnetic longitude is $300^{\circ}$, the modeled plasmaspheric density in December is greater than that in June, and the December to June ratio is in rough agreement with observations (for $L=2$ ). For this longitude the field line tilt is such that the southern end of a flux tube is farther from the geographic equator than the northern end, and the ionospheres are exposed to sunlight longer in December than in June. In contrast, for a field line whose geomagnetic longitude is $120^{\circ}$, the modeled plasmaspheric density in June is greater than that in December. For this longitude the field line tilt is reversed, so that the ionospheres are exposed to sunlight longer in June than in December.

While our results might seem to support the hypothesis that annual variations are caused by solar flux variations which are due to the tilt of the magnetic dipole axis, it should be noted that for both longitudes, diurnally averaged $\mathrm{O}^{+}$levels in the upper ionosphere vary in the same sense as plasmaspheric densities. This, together with the theoretical analysis given above, would suggest that plasmaspheric densities are sensitive to $\mathrm{O}^{+}$levels in the upper ionosphere. This was tested by raising $\mathrm{O}^{+}$levels with a vertical neutral wind and seeing the rise in plasmaspheric density. It should also be noted that interchanging the photoionization rates between hemispheres did not change the December to June ratio significantly. Furthermore, observational results [Clilverd et al., 1991] and previous modeling work [Clilverd et al., 1991; Rippeth et al., 1992] have shown that the annual variation of plasmaspheric density is correlated with the annual variation of $F 2$ peak density. Therefore we conclude that annual variations in plasmaspheric density are due to similar variations in ionospheric $\mathrm{O}^{+}$.

Acknowledgments. This work was supported by NSF grant ATM9116858. One of us (S.M.G.) was supported by NASA Marshall Space Flight Center through the graduate student training grant NGT-50368 for part of this work. Acknowledgment is also made to the National Center for Atmospheric Research, sponsored by the National Science Foundation, for the computing time used in this research.

The editor would like to thank A. Yau and one other referee for their assistance in evaluating this paper.

\section{References}

Carpenter, D. L., Electron density variations in the magnetosphere deduced from whistler data, J. Geophys. Res., 67, 3345, 1962.

Clilverd, M. A., A. J. Smith, and N. R. Thomson, The annual variation in quiet time plasmaspheric electron density, determined from whistler mode group delays, Planet. Space Sci., 39, 1059, 1991.

Comfort, R. H., J. H. Waite, Jr., and C. R. Chappell, Thermal ion temperatures from the retarding ion mass spectrometer on DE $1, J$. Geophys. Res., 90, 3475, 1985.
Geisler, J. E., On the limiting daytime flux of ionization into the protonosphere, J. Geophys. Res., 72, 81, 1967.

Guiter, S. M., T. I. Gombosi, and C. E. Rasmussen, Diurnal variations on a plasmaspheric flux tube: Light ion flows and $F$ region temperature enhancements, Geophys. Res. Lett., 18, 813, 1991.

Hedin, A. E., C. A. Reber, G. P. Newton, N. W. Spencer, H. C. Brinton, H. G. Mayr, and W. E. Potter, A global thermospheric model based on mass spectrometer and incoherent scatter data, MSIS, 2 , Composition, J. Geophys. Res., 82, 2148, 1977.

Helliwell, R. A., Exospheric electron density variations deduced from whistlers, Ann. Geophys., 17, 76, 1961.

Killeen, T. L., R. G. Roble, and N. W. Spencer, A computer model of global thermospheric winds and temperatures, Adv. Space Res., 7(10), 207, 1987.

Krinberg, I. A., and A. V. Tashchilin, Refilling of geomagnetic force tubes with a thermal plasma after magnetic disturbance, Ann. Geophys., 1, 25, 1982.

Lal, C., Global $F 2$ layer ionization and geomagnetic activity, $J$. Geophys. Res., 97, 12,153, 1992.

Park, C. G., Some features of plasma distribution in the plasmasphere deduced from Antarctic whistlers, J. Geophys. Res., 79, 169, 1974.

Rasmussen, C. E., S. M. Guiter, and S. G. Thomas, A two-dimensional model of the plasmasphere: Refilling time constants, Planet. Space Sci., 41, 35, 1993.

Rees, D., T. J. Fuller-Rowell, S. Quegan, R. J. Moffet, and C. J. Bailey, Simulations of the seasonal variations of the thermosphere and ionosphere using a coupled, three-dimensional, global model, including variations of the interplanetary magnetic field, J. Atmos. Terr. Phys., 50, 903, 1988.

Richards, P. G., and D. G. Torr, Seasonal, diurnal, and solar cyclical variations of the limiting $\mathrm{H}^{+}$flux in the Earth's topside ionosphere, $J$. Geophys. Res., 90, 5261, 1985.

Rippeth, Y., R. J. Moffet, and G. J. Bailey, Seasonal and longitudinal effects on plasmaspheric tube content, Adv. Space Res., 12(6), 179, 1992.

Sojka, J. J., and R. W. Schunk, Theoretical study of the seasonal behavior of the global ionosphere at solar maximum, J. Geophys. Res., 94, 6739, 1989.

Song, X.-T., and G. Caudel, Electron density near the plasmapause measured over one year by GEOS-2: A statistical analysis, J. Atmos. Terr. Phys., 49, 135, 1987.

Tarcsai, G., P. Szemeredy, and L. Hegymegi, Average electron density profiles in the plasmasphere between $L=1.4$ and 3.2 deduced from whistlers, J. Atmos. Terr. Phys., 50, 607, 1988.

Taylor, H. A., Jr., Evidence of solar geomagnetic seasonal control of the topside ionosphere, Planet. Space Sci., 19, 77, 1971.

Torr, M. R., and D. G. Torr, The seasonal behaviour of the F2-layer of the ionosphere, J. Atmos. Terr. Phys., 35, 2237, 1973.

Torr, D. G., P. G. Richards, and M. R. Torr, Ionospheric composition: The seasonal anomaly explained, in The Physical Basis of the Ionosphere in the Solar-Terrestrial System, Conf. Proc. 295, Advis. Group for Aerosp. Res. and Dev., Brussels, 1980.

T. I. Gombosi and C. E. Rasmussen, Space Physiss Research Laboratory, University of Michigan, Ann Arbor, MI 48109. (e-mail: tamas@sprlc.sprl.umich.edu; rasmussn@jupiter.eecs.umich.edu)

S. M. Guiter, Space Sciences Laboratory, NASA Marshall Space Flight Center, Huntsville, AL 35812. (e-mail: guiter@mpb.msfc.nasa. gov)

R. W. Schunk and J. J. Sojka, Center for Atmospheric and Space Sciences, Utah State University, Logan, UT 84322. (e-mail: schunk@cc.usu.edu; sojka@cc.usu.edu)

(Received May 21, 1993; revised September 12, 1994; accepted October 3, 1994.) 